\title{
How can the service user voice be best heard at psychiatric meetings?
}

\author{
Tom Burns and Diana Rose
}

\author{
Summary \\ Service user contributions to mental health conferences \\ are now routine. How effective they are at promoting \\ dialogue is not clear. We report a difficult exchange \\ following a presentation about coercive treatment, \\ with our individual reflections on what we learnt.
}

Suggestions are made to improve both the clinical practice and the dialogue.

\section{Declaration of interest}

None.
Tom Burns is Professor of Social Psychiatry at the University of Oxford. Diana Rose (pictured) is Reader in User-Led Research and Co-director of Service User Research Enterprise (SURE) at the Health Services and Population Research Department, Institute of Psychiatry, King's College London.

Most mental health conferences include service user and carer representatives and in many, service users and carers are included as presenters in the formal programme. Although this is widely welcomed, service users often comment that they experience their contributions as tokenistic, and professionals that they feel reluctant or unable to engage in meaningful dialogue. We report a difficult exchange about the service user experience of coercive treatment that took place between the two of us.

During a symposium on coercive treatments in psychiatry at the 2012 European Congress for Social Psychiatry in Geneva, D.R. presented a service user's perspective on such treatments, and physical restraint in particular. More heat than light was generated in the exchange and we were both left feeling bruised and perplexed. If two colleagues and friends of several years standing can fail to understand each other's position in such a setting, we believe that others may too. This is our attempt to learn from the situation. We still retain differences, so rather than attempt a synthesis we summarise the exchange and some thoughts on how to take the issue forward.

\section{A powerless struggle}

Coercive treatment is a controversial but very widespread aspect of psychiatric practice. Service users have very strong views on the issue and many call for its total abandonment. My presentation recognised the necessity of coercion in certain circumstances, especially detention, and in some aspects of treatment. However, it challenged the belief that professionals have an accurate understanding of its effects or that they pay adequate attention to minimising its negative impact. One factor leading to the difficulty of our exchange is that service users cannot avoid emotional language when presenting their experience but worry that it will disrupt dialogue with professionals in contexts such as the one reported. Nevertheless, I decided to be forthright and what followed was a more unedited description of the experience of coercion, with its petty humiliations (having to ask for the toilet door to be unlocked) and betrayals (promised escorted leave that simply never materialises).
Physical restraint was described in graphic detail with the sense of invasion, humiliation and fear from being held down and injected. That the procedure was generally carried out by male staff even with female patients added to its horror. Staff were cold and mechanical and almost never said anything, nor talked to the patient of the incident afterwards. For the service user it was experienced as a naked expression of their powerlessness, a grossly asymmetrical relationship bordering on the abusive. I emphasised that I spoke as both a service user and as a researcher, that the genuine motivations and kindness of some individual staff members was not in dispute, but this did not alter the analysis where my own experience was corroborated by my research. ${ }^{1,2}$

It is salutary to be obliged to reflect on these painful and potentially humiliating experiences. My perception differs on two fundamental points, one empirical and one theoretical. First, I believe most mental health staff are sympathetic to the distress involved; we choose this work because we recognise how awful mental illnesses are. My observations are that usually we do actively try to minimise the distress in simple ways such as repeatedly using the patient's name and explaining why they are doing what they are doing. We try to be reassuring: 'I know it's awful but you will feel better soon', or similar. Sometimes we fail and clearly this is an area where improved training would help.

The second difference is more fundamental and conceptual. Coercion in psychiatry is only justified if you accept that there really is something special about mental illness, that people are not their normal selves when acutely ill. Without such a view, compulsory treatment is indefensible and any analysis of the experience of coercion without acknowledging it strikes me as incomplete. It is ultimately the illness that gives rise to the behaviour and that causes the distress and humiliation, and both sides may be distressed by it. Staff distress in restraint is not comparable to that of the patient, but I know from personal experience that it is real. It is undignified for all involved to be grappling like this. It can be painful to see a patient that you know and often like in this position, no matter how necessary you consider it. I have seen breast cancer surgeons having to make the same point - that it is the cancer not the surgery that is fundamentally responsible for the disfigurement.

What can be done to improve things? Diana's vivid presentation suggests two immediate changes in clinical practice. First, that female staff always take the lead on the restraint of female patients and, if possible, for most, if not all, staff involved 
in the procedure to be female. The implications of men holding down distressed women are too obvious to need detailed justification. Second, make it a requirement that staff go back to the patient soon after the treatment to explain why they did what they did. This is even more important when the patient remains angry and hostile. It still makes a difference to both parties and should be done more than once. I have found when placing patients under a section that seeing them as soon as possible directly after and explaining my reasoning (even when forcefully rejected) is remembered, and I think it helps reduce brooding and resentment.

What of the presentation of the service user's perspective? The use of emotionally charged language was brave and, in my opinion, necessary. I have three suggestions for a more productive dialogue. The first is lifted from family therapists: to restrict descriptions of motivation and feelings to those of the person feeling them, here the patient. Thus, staff are not 'cold and mechanical' but 'appear cold and mechanical'. Staff can speak for themselves. The second is to make some acknowledgement of the special nature of mental illness and the inevitably somewhat paternalistic assumption that an acutely ill patient is in some ways not their normal self. Even if one has reservations about the legitimacy of such a paternalistic position, staff behaviour can only be understood in that light. The third is about language. I have used the term patient rather than service user throughout my response. I understand the current desire to displace this term and, although I think it is mistaken, usually comply with it. However, it does not work in the situation of coercive treatment which implies that the patient is not making rational choices that reflect their settled position. Here the term patient seems to me essential. The sick role carries important diplomatic immunity for both sides, never more needed than in such painful exchanges. We would probably all do better to value it.

\section{The importance of institutions}

First, I would like to comment on what I said about staff motivations. This is emphatically not an ad hominem argument. There are a plethora of institutional arrangements that sanction if not actively encourage coercive treatment in psychiatry. Consultant psychiatrists in particular go through many years of training, are schooled up in mental health law and the discourse of risk, and are subject to guidance from both professional bodies and the National Institute for Health and Care Excellence. Consultant psychiatrists are responsible for junior doctors and the rest of the multidisciplinary team, and they are the ones who will face litigation if things go wrong. So I was not impugning staff motivations, rather criticising a system which positions them in such a way that they feel obliged to engage in practices, such as control and restraint and rapid tranquillisation, that patients experience negatively. But I am a social scientist and never resort to blaming individuals - it is institutions, their cultures and norms that concern me. However, in terms of the institution that is a psychiatric hospital, I agree that we are 'patients', although my reasoning is rather different to Tom's. We are patients because we are passive and have little agency.

On the philosophical point about the special nature of mental illness, I am not persuaded of this and the use of the cancer comparison indicates some uncertainty. Cancer patients cannot be forced to have surgery whatever subtle pressures are operating. I am inclined to give psychiatric patients the same option when it comes to emergency medication, although I can see a case for detention. To take it to its limit, the prone position can be lethal: people have died. So as a first step let us remove that.

Has this exchange any lessons for how service users, service user researchers and mental health professionals might engage in more productive dialogue especially on such emotive issues as coercion? I am not sure. I know many service users who are against any form of coercion at all and this exchange will not change their minds. But if we have been able to listen to one another and produce some suggestions for change while retaining some, admittedly vital, differences, then perhaps our original clash will not have been in vain.

Tom Burns, MD, DSC, FRCPsych, University of Oxford, Department of Psychiatry Warneford Hospital, Oxford; Diana Rose, PhD, Health Services and Population Research Department, Institute of Psychiatry, King's College London, UK

Correspondence: Tom Burns, Professor of Social Psychiatry, University of Oxford, Department of Psychiatry, Warneford Hospital, Oxford OX3 7JX, UK. Email: Tom.burns@psych.ox.ac.uk

First received 10 Sep 2012, final revision 25 Jan 2013, accepted 13 Feb 2013

\section{References}

1 Katsakou C, Rose D, Amos T, Bowers L, McCabe R, Oliver D, et al. Psychiatric patients' views on why their involuntary hospitalisation was right or wrong: a qualitative study. Soc Psychiatry Psychiatr Epidemiol 2012; 47: 1169-79.

2 Evans J, Rose D, Flach C, Csipke E, Glossop H, Mccrone P, et al. VOICE: developing a new measure of service users' perceptions of inpatient care, using a participatory methodology. J Ment Health 2012; 21: 57-71. 